\title{
The Importance of Facts and the Role of Academic Publishers in Today's World-A Publisher's View
}

\author{
Daniel Schiff, MD ${ }^{1}$ \\ ${ }^{1}$ Publisher, Thieme Medical Publishers, New York, New York \\ J Hip Surg 2017;1:v.
}

An academic publisher's role is to promote proper validation of scientific findings by supporting our editors in the peerreview process, certifying these findings by publishing them in our journals, and ensuring the distribution and archiving of these results in collaboration with multiple partners and in particular the academic libraries.

In these activities we help build, protect, and conserve the integrity of the corpus of scientific knowledge, which spurs the thoughtful pursuit of human progress.

As science publishers and as citizens, we formally state that we are committed to support public discourse based on corroborated facts and that we shall not adapt the editorial policies of our journals under any commercial or political pressure. We have and will continue to validate and distribute peer-reviewed data and content, whether consistent or not with assumed truths.

Together with our partners in the library community we have and will ensure wide access to the ever expanding scientific corpus, to constructively contribute to the public debate on how to create a better, safer, and more generous world. 
